\title{
Productivity Shocks and Labour Market Outcomes for Top Earners: Evidence from Italian Serie A
}

\author{
Vincenzo Carrieri, ${ }^{*}, \dagger,+$ Andrew M. Jones, $\S, \emptyset$ and Francesco \\ PRINCIPE**
}

*Department of Law, Economics and Sociology, "Magna Graecia” University, Catanzaro, Italy

$\dagger R W I$ Research Network, Essen, Germany

$\$$ Department of Economics, Lancaster University Management School, Lancaster, Bailrigg LA1 $4 Y X, U K$

$\S$ Department of Economics and Related Studies, University of York, York, UK

\Centre for Health Economics, Monash University, Melbourne, Australia

**Erasmus School of Economics, Erasmus University Rotterdam and Erasmus Center for Applied Sports Economics (ECASE), Rotterdam, The Netherlands

\begin{abstract}
How are top earners affected by productivity shocks? We address this question using a unique longitudinal data set on the universe of professional football players in the Italian Serie A, representing $20 \%$ of top earners in Italy. We use traumatic injuries and adopt an IV strategy to provide causal estimates of the impact of productivity shocks on several labour market outcomes. We find that a 30-day injury substantially affects the probability of contract renegotiation and reduces net wages by around $12 \%$. We show that this large penalty is due to employer's precautionary motives rather than to shock-induced reduction in current player's performance.
\end{abstract}

\section{Introduction}

The dynamics of earnings of those in the right tail of the income distribution has been the subject of keen economic interest in recent years. Since the 1970s, top income shares started to rise substantially in all developed countries and, in particular, the English-speaking ones (Atkinson, 2017, Atkinson, Piketty and Saez, 2011). For instance, from 1980 to 2016, the share of national income received by the top $1 \%$ grew from $16 \%$ to $21 \%$ around the World (Alvaredo et al., 2018). Higher growth has been reported in the US where the top $1 \%$ share grew from $11 \%$ to $20 \%$. In Europe, the top $1 \%$ share increased from $10 \%$ to $12 \%$ over the same period (Alvaredo et al., 2018). Moreover, looking at the composition a substantial change has been found. In fact, in all the countries for which data are available, there has been a shift from capital income to labour income (income from employment, self- 
employment and pensions) as the main component of top income shares, especially during the 1980s and 90s (Alvaredo et al., 2013). For example, in this period, the share of the top $0.1 \%$ of incomes earned in the labour market grew by $20 \%$ points in the US reaching $45 \%$ of the total (Franzini, Granaglia and Raitano, 2016). In Italy, the growth of the share of the top $1 \%$ and $0.1 \%$ was $1.9 \%$ and $0.9 \%$ points over the period 1974-2009 (Franzini et al., 2016). In line with the other developed countries, a substantial shift from capital to labour income has been reported. For instance, among the top 1\%, the share of labour earnings accounted for $46.4 \%$ of the total in 1980 while they accounted for $70.9 \%$ of the total in 2008 . Similarly, among the $0.1 \%$ richest segment of the population, the share of labour earnings rose from $29.5 \%$ to $66.2 \%$ over the same period (Franzini et al., 2016). Thus, the labour market seems to be fertile ground for the escalation of contemporary society's extreme inequalities. This leads to the phenomenon known as 'working super-rich' or 'Superstars'.

A number of analyses have focused on several dimensions of this phenomenon, including the determinants of high earnings and their effects on overall inequality (see section II for more details). But how are these high earners affected by productivity shocks? Due to the lack of relevant data, this question has remained substantially unexplored so far. However, understanding how productivity shocks affect the labour market prospects of the 'working super-rich' and whether this differs from 'ordinary' workers is useful to get insights on the peculiarities of the market in which the super-rich operate and, ultimately, to appreciate the dynamics behind the rise of extreme inequalities in the labour market.

This paper aims to address this gap by providing evidence on the relationship between productivity shocks and labour market outcomes of individuals in the top tail of the earnings distribution. In particular, the aim of this research is to analyse traumatic injuries as a source of exogenous variation in professional football ${ }^{1}$ players' productivity to provide estimates of the causal impact of this shock on two key labour market outcomes: annual net wages and the probability of renegotiation of the contract between the employer (the club) and the employee (the player). To analyse this issue, we have created a unique longitudinal data set recording wages, performance, popularity and injuries for the universe of football players of the Italian Serie A followed from 2009 to $2014 .^{2}$ This data set was built by merging information from several reliable sources of data that are described below.

The focus on data from professional football is based on a number of considerations. First, the football industry is a sector with an extremely high risk of productivity shocks due to injury. According to Hawkins and Fuller (1999), the overall level of injury to professional footballers is around 1000 times higher than for other industrial occupations that are generally regarded as high-risk such as construction and mining. Second, the football market is based on short-term contracts (generally 3-4 years), with high levels of contract renegotiation and players being traded in every market window; this generates a large variation in wages across seasons. Third, football players constitute a large share of top earners. In Italy in 2003 about $20 \%$ of the top 500 earners, representing the top $0.01 \%$ of

\footnotetext{
${ }^{1}$ Throughout this paper, we use the word 'football' to indicate international game of football as played in the Italian Serie A. In the US, this is often known as 'soccer'.

${ }^{2}$ Italian Serie A is one of the five most followed football leagues in the world, alongside the Premier League (England), Bundesliga (Germany), La Liga (Spain) and Ligue 1 (France). Yearly, it has a turnover of about 1.9 billion Euros. Among the 'big five' leagues, Italian Serie A is the one with the highest incidence of the wage bill on the clubs' costs, absorbing about $70 \%$ of the clubs' total earnings (Deloitte, 2017).
} 
the distribution, were football players or managers (Franzini et al., 2016). Fourth, as argued by Kahn (2000): 'professional sports offers a unique opportunity for research. There is no research setting other than sports where we know the name, face, and life history of every production worker and supervisor in the industry'.

Professional sports represent a unique laboratory for research due to readily available data on individual productivity that allows a perfect match between employer (the club) and employee (the player) to estimate team production functions (Szymanski, 2007). In recent years, the use of sports data has been rising. Recent contributions include: Stoecker, Sanders and Barreca (2016), who examine the impact of influenza transmission on mortality by looking at local sports team success through the participation in Super Bowl of the National Football League (NFL) ${ }^{3}$; Hanson, Jolly and Peterson (2017), who exploit a difference-indifferences framework in order to examine the effects of the 'Crown of the Helmet Rule' on players' injuries in the $\mathrm{NFL}^{4}$; and Leive (2018) who compares mortality between Gold and Silver medallists in Olympic Track and Field. Last but not least, Mange and Philips (2016) use data on Major League Baseball players subject to the Vietnam War draft to show how early career interruptions can lead to persistently lower performance. Interestingly, they also show that results from sports are readily generalizable to other superstar professions where careers advance rapidly with short stays at the top. We discuss this point in the concluding section of the paper.

Our paper makes a number of contributions to the literature. First, as discussed above, it focuses on the consequences of productivity shocks for those on top incomes, for whom there is scant evidence available. Second, it provides evidence of the causal relationship between labour market outcomes and health shocks. While a large literature (surveyed in section II) shows a general negative association between productivity losses due to health shocks and earnings, a causal relationship is difficult to establish. This is due to the possible endogeneity of injuries in relation to labour supply, which may result from both simultaneity and unobserved heterogeneity bias (Lindeboom and Kerkhofs, 2009; Cai, 2010). In this paper, we adopt a study design that exploits the unpredictability of traumatic injuries that a player may incur, the longitudinal nature of our data set, which allows us to sweep out individual time invariant characteristics, and an instrumental variable strategy (using the average number of yellow cards received by the rest of the team as an instrument). Third, our data allows for a deeper analysis of the main mechanisms behind the impact of a productivity shock, disentangling the effect mediated through the player's performance and the one generated by human capital depreciation, inducing the club to offer a lower wage for precautionary reasons. Last but not least, our analysis on the effect of injury on the probability of renegotiation has relevant implications for the football industry and in particular for fixing the optimal length of players' contracts from both the player and the club perspectives.

We find that productivity shocks affect the labour market outcomes of football players but in a very particular way compared to 'ordinary' workers. First, in terms of magnitude, we find that a 30-day injury results in a reduction of the following year's wage by about $12 \%$. This effect is significantly higher than the evidence typically found for other

\footnotetext{
${ }^{3}$ American Football League.

${ }^{4}$ Implemented in 2013 by the National Football League (NFL), it aims at reducing incidence of concussions and head injuries by penalizing a player who intentionally initiates contact with another player using the top of his helmet.
} 
workers. Interestingly, we also find that this reduction can be explained more in terms of precautionary measures being taken by the club rather than through any direct effect that the injury might have had on performance. Consistently, the injury is found to be positively associated with the probability of wage renegotiation with the same or another club, at the end of the season. This is particularly true for more severe injuries and highlights the nature of the length of a player's contract as a risk-sharing mechanism between the player and the club. Finally, we find that the main factors addressed by the literature about the determinants of high earnings, such as performance and popularity, have a significant impact on the players' wages. These results are robust to a number of model specifications and to alternative measures of shock and may be generalizable to other categories of the superstars whose earnings and careers reflect fierce competition with only few workers being able to reach the top of the profession.

The remainder of the paper is structured as follows. Section II provides some insight into the literature on the consequences of health shocks for employees' outcomes and the theoretical and empirical evidence about the determination of wages among the superrich. Section III describes the data gathering process, explaining the main variables and providing some descriptive statistics. Section IV discusses the empirical methodology. Section V presents the results and the final section summarizes and concludes.

\section{Productivity shocks and top incomes}

This paper is grounded in two main strands of the literature. First, the literature about the impact of productivity shocks due to health and labour market outcomes. Second, the theoretical and empirical literature about the determinants of top incomes, in particular the working super-rich, defined as individuals who receive high earnings due to their employment.

The relationship between health shocks and labour market outcomes is well established in the economic literature, with empirical evidence provided for both developed countries (e.g. García-Gómez, López and Nicolás, 2006) and for developing countries (e.g. Wagstaff, 2007, Wagstaff and Lindelow, 2014, Mitra et al., 2016). However, most of the contributions focus on aspects of labour participation as the main outcome (e.g. Jones, Rice and Roberts, 2010, Cai, Mavromaras and Oguzoglu, 2014) and use data based on elderly workers (e.g. Bound et al., 1999; Disney, Emmerson and Wakefield, 2006; Lee and Kim, 2008; Trevisan and Zantomio, 2016). The main findings show that health shocks have a negative impact on several dimensions, including consumption and income. For example, García-Gómez and López Nicolás (2006), using Spanish data from the European Community Household Panel, find that a transitory health shock has a negative impact on workers' labour income that ranges between 1,400 and 1,700 Euros, according to the length of the period of incapacity. Halla and Zweimüller (2013) find that Austrian workers who experienced health shocks while commuting incur persistent income losses of about $2-3 \%$, depending on their attachment to the labour market. García-Gómez et al. (2013), using Dutch hospital and tax register data, find that an acute hospital admission lowers the employment probability by $7 \%$ and results in a 5\% loss of personal income two years after the shock.

A second strand of literature is mainly based on the 'superstar' theories proposed in the seminal contributions of Rosen (1981) and Adler (1985), as the basis for disentangling the determinants of super-earnings. In fact, they both argue that superstars arise in markets 
characterized by imperfect substitution on the demand side and joint consumption on the supply side, which generate a demand concentration towards the better performers (i.e., professional athletes, singers, artists, etc.), who 'win and take all'. However, while for Rosen (1981) marginal differences in talent and hence productivity are magnified into huge earnings for the most talented due to the convexity of the revenue function, Adler (1985) argues that popularity is the main determinant of superstars' earnings.

From an empirical point of view, a number of researchers have made use of sports data to test the superstar theories. For example, Lucifora and Simmons (2003) investigate superstar effects in wage determination among football players in the Italian Serie A. They find earnings to be highly convex in measures of performance, after controlling for a set of personal characteristics and team fixed effects. Carrieri, Principe and Raitano (2018) find that talent, popularity and agent's bargaining power are all jointly significantly associated with higher wages of Italian football players but their impact is very heterogeneous across the distribution of earnings. Franck and Nüesch (2012), using data from the German Bundesliga, find that both talent and popularity significantly contribute to increasing the market value of superstars. Other studies (e.g. Mullin and Dunn, 2002, Treme and Allen, 2009, 2011) focus on American professional sports, finding a positive effect of both measures of performance and media exposure on the entry earnings of baseball (MLB) and basketball (NBA) players.

Building on these two strands of literature, this study aims to integrate the evidence and investigate the impact of productivity shocks due to injuries on the labour market outcomes for a specific category of the working super-rich: the professional football players of the Italian Serie A. The interaction of these two strands of literature is interesting for a number of reasons. First, professional football players face a faster deterioration of human capital than the norm. On one hand, this translates into a relatively short career where they earn exceptionally high wages but for a short time span. On the other hand, the faster deterioration of human capital involves an evaluation by the employer not only of the employee's current productivity but also of their potential future productivity. Productivity shocks due to injuries might then raise employer's concern about potential future depreciation in the employee's human capital and thus produce more negative consequences for their earnings. Last but not least, the length of the contracts is particularly relevant as it might act as an implicit risk-sharing mechanism between the employer and the employee against the risk of injuries. Thus, estimating the impact of injuries has relevant implications for fixing the optimal length of the contract.

\section{Data and variables}

We created an original data set recording information about wages, performance, injuries and other individual characteristics of the universe of professional players of the Italian Premier League (Serie A), using several data sources. We have data relating to 469 players who had at least one appearance in the 2013-14 football season. We exclude goalkeepers, following the standard approach of this kind of literature (Lucifora and Simmons, 2003), since their performance is measured differently and they have a different exposure to the risk of injury compared to outfield players. The careers of these players were followed over a 5-season period, from 2010-11 to 2014-15. This provides a longitudinal data set of 1,585 observations. The panel is unbalanced. In fact, the relegation/promotion system 
between Serie A and Serie B and the transfer market across national and international clubs generates a relatively large turnover of players in the league. ${ }^{5}$

Data on players' yearly wages - recorded net of taxes and excluding any performancerelated bonus - are taken from an annual report, published at the beginning of each football season by the most influential Italian sport newspaper, La Gazzetta dello Sport. Importantly, this focuses only on the fixed part of the wage. This allows for a better understanding of the effect of the shock on the stock of human capital and reduces concerns about reverse causality, since the dependent variable does not include bonuses that depend on performance. Moreover, to assess the impact of injuries on renegotiation of contracts, we use a dichotomous variable with value 1 if there has been a change in the fixed part of the contract wage at the end of the season (with the same club or a new one, if the player had been traded during the transfer market window), or value 0 in case of no changes. Unfortunately, we have no data on the players' length of the contract since this information is not publicly available. However, aggregate data suggests an average length of 2.1 years in Italian football (CIES Football Observatory 2018). We expect a similar average length in our data set since we observe the universe of football players in the pivotal season 2013-14 for 5 years.

Information about individual player characteristics (i.e. birth year, position on the pitch and international appearances) and performance (such as, goals and assists) are extracted from the website transfermarkt.com ${ }^{6}$. In addition, in order not to underestimate the performance of midfielders and defenders, we collected data about each player's overall performance. These were recorded as the average rating of the three most read Italian sport newspapers, La Gazzetta dello Sport, Il Corriere dello Sport and Tuttosport, which each rate the players' performance after every match, with a scale that ranges from 0 (poor performance) to 10 (excellent performance). In fact, most of the marks assigned by the journalists range between 4 and 8 .

With respect to injuries, we collected data about any injury that occurred in the seasons analysed. In particular, all the injuries were categorised according to the terminology and classification of Mueller-Wohlfahrt et al. (2012). Alongside the type of injury, we collected information about the impact of the injury, proxied through days off and measured as the period of time in which the player was not available to participate in the sports activity of the club (training and matches) and the number of official championship matches missed by the injured player. These data are taken from footballmarkt.com. Furthermore, since a player could incur more than one injury in the same season, we consider the number of days off due to either muscular or traumatic injury and we include a dummy variable to control for the reoccurrence of the same injury during the season.

Concerning the clubs, we analysed the annual balance sheets as approved by the directors of the 27 clubs, matched with the players who took part in Serie A for the seasons considered. In particular, information was recorded about five balance sheet items: total

\footnotetext{
${ }^{5}$ There are 20 teams taking part in Serie A. At the end of the season, the last three in the table are relegated to the second division (Serie B) and replaced by the first three from Serie B. Players are traded during two yearly market windows, i.e. in summer (usually by the end of July) and in winter (usually by the end of January). Turnover usually involves heterogeneous types of players, both less talented players traded with teams playing in minor leagues and more talented players traded with top European clubs. This helps to mitigate concerns about selective attrition.

${ }^{6}$ A German website recording information about football statistics, results, fixtures and news. Data from transfermarkt.com have been used in previous economic studies (i.e. Bryson, Frick and Simmons, 2013).
} 
wage expense, net sales, earnings before taxes (EBT), revenues from ticketing and revenues from television rights.

Other variables include a proxy of popularity, measured as in Carrieri et al. (2018) through the preseason number of Google search results obtained each year for each player ${ }^{7}$ and several other characteristics, related to both clubs and players, which are used as controls in the estimation. These are presented, along with some summary statistics for all variables, in the next section.

\section{Descriptive statistics}

All the variables included in our dataset, along with their means and standard deviations, are presented in Table 1. According to our data, the average annual net wage of a player in Italian Serie A amounts to about 840,000 Euros, but with a very large standard deviation (891,000 Euros). Figure 1 shows the non-parametric estimate of the wage distribution for the reference football season 2013-14. The distribution is positively skewed with a long upper tail. This supports the idea of a restricted number of players who earn huge wages compared to the rest of the distribution and it is consistent with the theories of 'superstars' emerging (Rosen, 1981, Adler, 1985). Indeed, the Gini index within the sampled football players group is 0.47 , showing a large degree of inequality even within this group of privileged individuals. $^{8}$

Concerning the length of the contract, aggregate data suggests an average length of 2.1 years in Italian football (CIES Football Observatory 2018) with the exception of contracts for both younger and older players, that are often characterized by shorter-term arrangements (Carmichael, Rossi and Simmons, 2012). Contracts can be renegotiated before the expiry date (often to compete with claims by other teams) and in some cases automatic earnings increases are established by the contract according, for example, to the number of games played during a season. Our data show that approximately $65 \%$ of players renegotiate their contract each year ( $56 \%$ renegotiate within the same team). This reinforces the focus on a particular type of job market in which the contracts quickly reflect the changes in terms of both productivity (performance and popularity) and health shocks.

Concerning injuries, $50.5 \%$ of players included in the sample had at least one injury, of which $41.7 \%$ were muscle related, while the remaining $58.3 \%$ were caused by some kind of traumatic event, such as fractures, cruciate ligament rupture, etc. The re-occurrence rate is $10.4 \%$. In the reference season, 2013-14, on average a player spent 21 days off activity and missed 4 official matches. Moreover, information about the exact date of the injury was also collected. Figure A.1 (in the Appendix) shows the percentage distribution of the injuries alongside the different months of the year. Interestingly, the highest percentage of injury was recorded in September (about 15\%), which is the first month of official matches after the summer break, followed by the winter months, probably due to worse weather

\footnotetext{
${ }^{7}$ The data refer to the same day for each player. They have been collected browsing 'name-surname-team' in order to reduce any bias due to homonymy with respect to some surnames, which have higher incidence in Italy.

${ }^{8}$ Our estimates of the Gini index are in line with results found for other soccer leagues. For instance, Send (2016) finds a Gini of 0.51 considering the earnings of the German Bundesliga players in the 2014-15 season. A higher inequality emerges instead in the US Major Soccer League: Reilly and Witt (2007) find a Gini of 0.628 in 2007 (0.569 excluding from the computation David Beckham who was the most highly paid player at that time).
} 
TABLE 1

Sample characteristics.

\begin{tabular}{llr}
\hline Variable & Description & Mean (SD) \\
\hline $\begin{array}{l}\text { Dependent variable } \\
\text { Wage }\end{array}$ & Net earnings (pre-season values) in thousands/€ & $875.1(911.7)$ \\
Log wage & Log of net earnings (pre-season values) & $6.38(0.87)$ \\
Renegotiation & Dummy for contract's renegotiation & $0.64(0.48)$ \\
Individual controls & & \\
Age & Age (years) & $26.6(4.2)$ \\
Age square & Age squared & $725.8(226.7)$ \\
Position & Dummies for defenders (40.2\%), midfielder (39.9\%) and forward (19.9\%) \\
Captain & Dummy for the team's captain & $0.034(0.181)$ \\
Minutes played & Minutes played during the season & $1352.8(1068.3)$ \\
Total international caps & Number of caps with the national team up to 2014-15 & $15.75(25.10)$ \\
Total Under-21 caps & Number of caps with the U21 national team up to 2014-15 & $5.85(8.68)$ \\
International caps & Number of caps with the national team during the season & $2.01(4.65)$ \\
Under-21 caps & Number of caps with the U21 national team during the season & $0.37(1.59)$ \\
Player's performance & & \\
Grade & Mean grade by newspapers during the season & $5.77(0.41)$ \\
Goal & Goals scored during the season & $1.93(3.50)$ \\
Assist & Assists served during the season & $1.28(2.04)$ \\
Index of popularity & & \\
Popularity & Google search results (million) & $4.21(9.37)$ \\
Index of health shock & & \\
Injury & Dummies for the kind of injury & \\
Days-off traumatic & Number of days off due to traumatic injury & $11.08(38.77)$ \\
Days-off muscular & Number of days off due to muscular injury & $4.77(12.90)$ \\
Reoccurrence & Dummy for the re-occurrence of the same kind of injury & $4.79(7.35)$ \\
Matches off & Total number of matches missed due to any injury & $4.04(7.12)$ \\
Instrumental variable & & Number of teammates' avg. yellow cards \\
Yellow cards & & \\
\hline & & \\
& &
\end{tabular}

conditions and player fitness. This heterogeneity is controlled for through the inclusion of a variable recording the timing of the injury (i.e. the month in which the injury occurred) in some model specifications.

In order to ensure that the two groups do not differ systematically due to pre-injury observable characteristics and to investigate possible concerns of selection bias, Figure 2 shows the non-parametric wage distribution at time $t-1$ comparing the group who had at least one traumatic injury during the season $t$ and the control group of those who did not. The two distributions are highly similar, showing a long upper tail and an asymmetric distribution, a characteristic already observed above, when analysing the whole sample. However, as reported in Table 2, there is a large amount of dispersion but the distribution is fairly similar within both groups. The within-group inequality is slightly larger among the injured players, with Gini indices of 0.45 and 0.43 , respectively.

Furthermore, we report descriptive statistics for the relevant covariates in Table 3. We do not find statistically significant differences in the main covariates across the two groups and 


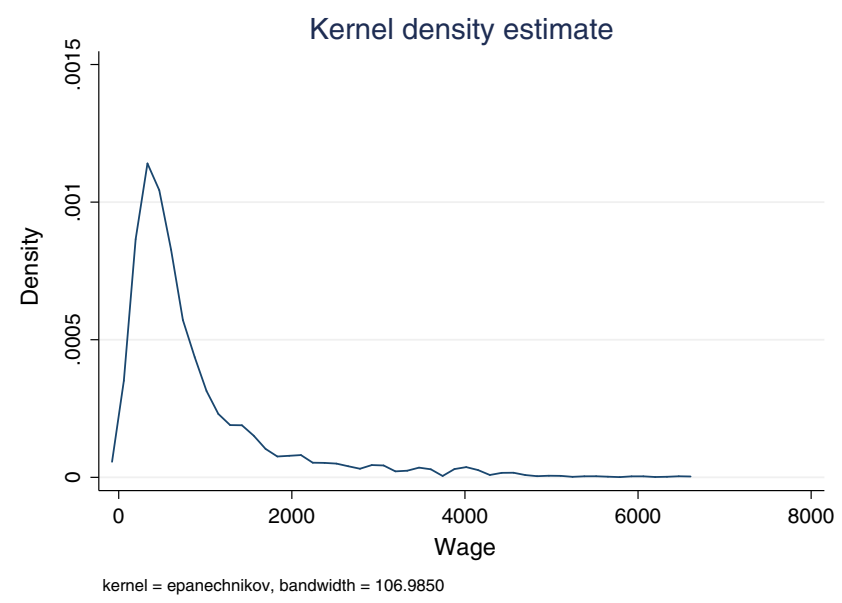

Figure 1. Kernel density estimate of annual net wages

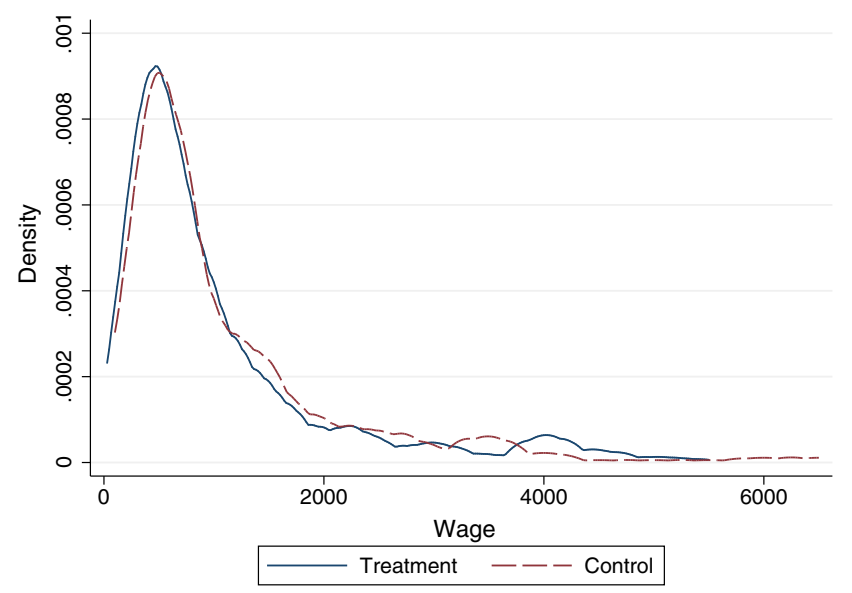

Figure 2. Kernel density estimate of annual net wages: groups comparison

this reinforces the idea that such a shock may plausibly be regarded as unpredictable. Only the mean ages across these groups show a statistically significant but negligible difference, being 27.9 and 27.3, respectively. As expected, those injured played 200 minutes less than their counterparts. Importantly, we do not find statistically significant pre-injury differences in our main outcome, i.e. the wage. The injured players on average earned 95,000 Euros more than the controls. However, even if the average wage gap between the two groups seems to be large in absolute terms, it is important to notice that since the paper analyses a sample of individuals with very high earnings, the relative size of the gap is less concerning. A Student's t-test of the means suggests that these differences are not statistically significant at the $5 \%$ level.

Finally, Table A.1 reports the clubs' characteristics regarding some relevant balance sheet items. The clubs have great differences in wage bills, with the richest clubs paying almost 7 times more than the bottom ones. Indeed, this inequality is also reflected in the distribution of television rights, which is fairly skewed among the clubs. Substantial 
TABLE 2

Wage distribution: percentiles and Gini Index.

\begin{tabular}{lccc}
\hline & Total & Treatment & Control \\
\hline Mean & 985.9 & $1,050.9$ & 955.8 \\
Standard deviation & 941.3 & $1,025.1$ & 898.9 \\
Minimum & 30 & 30 & 30 \\
p10 & 300 & 300 & 300 \\
p25 & 400 & 400 & 400 \\
p50 & 650 & 700 & 600 \\
p75 & 1,200 & 1,200 & 1,100 \\
p90 & 2,100 & 2,400 & 2,100 \\
p99 & 4,500 & 4,900 & 4,200 \\
Maximum & 6,500 & 5,500 & 6,500 \\
Gini Index & 0.474 & 0.453 & 0.435 \\
\hline
\end{tabular}

TABLE 3

Within group characteristics.

\begin{tabular}{|c|c|c|c|c|c|c|c|c|c|c|}
\hline & \multicolumn{4}{|l|}{ Treated } & \multicolumn{4}{|l|}{ Controls } & \multirow{2}{*}{$\begin{array}{l}\text { Mean } \\
\text { difference }\end{array}$} & \multirow[b]{2}{*}{$P$-value ${ }^{1}$} \\
\hline & Mean & $S D$ & Min & $\operatorname{Max}$ & Mean & $S D$ & Min & $\operatorname{Max}$ & & \\
\hline Wage & $1,050.9$ & $1,025.1$ & 30 & 5,500 & 955.7 & 898.9 & 30 & 6,500 & 95.2 & 0.11 \\
\hline Caps & 22.49 & 8.95 & 1 & 38 & 24.5 & 9.51 & 0 & 38 & 2.01 & 0.005 \\
\hline Minutes & $1,651.9$ & 814.0 & 8 & 3230 & $1,811.6$ & 904.9 & 0 & 3,643 & 159.6 & 0.004 \\
\hline Age & 27.9 & 4.1 & 19 & 40 & 27.3 & 3.8 & 18 & 39 & 0.6 & 0.01 \\
\hline Goal & 2.56 & 4.14 & 0 & 28 & 2.52 & 3.68 & 0 & 29 & 0.04 & 0.84 \\
\hline Assist & 1.72 & 2.29 & 0 & 12 & 1.67 & 2.15 & 0 & 14 & 0.05 & 0.72 \\
\hline Grade & 5.76 & 0.43 & 3.33 & 6.75 & 5.78 & 0.39 & 3.67 & 6.7 & 0.02 & 0.33 \\
\hline Popularity & 0.45 & 0.89 & 0.003 & 9.20 & 0.39 & 0.87 & 0.002 & 9.66 & 0.06 & 0.28 \\
\hline
\end{tabular}

Notes: ${ }^{1} P$-value for the Student t-test of means comparison. $\mathrm{H}_{0}$ diff $=0 ; \mathrm{H}_{\mathrm{a}} \operatorname{diff} \neq 0$.

heterogeneity emerges among Serie A clubs thus we control for team fixed effects in our specifications.

\section{Empirical strategy}

In order to identify the causal effect of a productivity shock due to injury on labour market outcomes, we first exploit the detail of our data that allows us to distinguish the main cause of injury. Muscular injuries might depend to some extent on a player's effort to improve their fitness through physical training. Thus, we focus on traumatic injuries which represent from 40 to $75 \%$ of all acute injuries (Hawkins and Fuller, 1999) - and are largely due to physical clashes during games or training sessions. Evidence reported in sports medicine (see, Hawkins and Fuller, 1999; Bahr and Krosshaug, 2005 for a review) finds that the frequency of physical clashes is one of the main sources of traumatic injuries in professional football. We combine this information with the panel structure of our data that allows us to include player fixed effects to take into account time-invariant observed and unobserved individual characteristics, such as players' attitudes to training and genetic 
or physical characteristics, which might predispose them to injuries and also have an impact on the outcomes.

Thus, the model to be estimated is the following Mincerian wage equation:

$$
\log (W)_{i t}=\beta_{0}+\beta_{1} X_{i, t-1}+\beta_{2} P_{i, t-1}+\beta_{3} S_{i, t-1}+\beta_{4} \text { Season }_{t}+\beta_{5} \text { Team }_{j, t}+\mu_{i}+u_{i t}
$$

where the dependent variable is the logarithm of the annual player's wage in season $t$, net of taxes and bonuses. The coefficient of interest is $\beta_{3}$, where the covariate $S_{i t-1}$ represents the incidence of the shock through the number of days off due to the reported injury. $X_{i t-1}$ represents a set of individual time-varying characteristics that are used as controls. All the variables are time lagged to reduce potential reverse causality concerns. Specifically, we include the following controls: age, the square of age, a number of experience related characteristics (e.g. the number of international appearances with either the senior national team or the under $21 \mathrm{~s}$, a dummy for the team's captain), the total number of minutes played in the previous season. Moreover, we include dummies for the player's position on the pitch (defenders, midfielders and forwards), dummies to distinguish the players nationality (Italian, EU and extra EU), and in some specifications, we also include a control for the timing of the injury (i.e. the month in which the injury incurred $)^{9} . P_{i t-1}$ is a set of covariates which includes proxies of talent and popularity to take into account the main explanations of superstars' earnings (Rosen, 1981, Adler, 1985). These are goals scored, assists served, ratings given by the newspapers and the number of Google search queries. Season $t$ is a vector of season fixed effects $\mu_{i}$ are player fixed effects which account for time-invariant player characteristics, while $\mathrm{u}_{\mathrm{it}}$ is the idiosyncratic error term.

While the fixed effects model shown in equation (1) controls for time invariant individual characteristics, unobserved idiosyncratic factors affecting both the injury and the outcome of interest might be still an issue. Thus, to address remaining concerns about the endogeneity of the injury and possible measurement errors, we use a fixed-effects instrumental variables strategy (FE-IV). This leads to estimate the following first-stage equation:

$$
S_{i t-1}=\theta_{0}+\theta_{1} X_{i, t-1}+\theta_{2} P_{i, t-1}+\theta_{3} z_{i, t-1}+\theta_{4} \text { Season }_{t}+\theta_{5} \text { Team }_{j, t}+\varepsilon_{i t}
$$

where the instrument $z$ is the average value of the yellow cards received by team $j$, excluding those of player $i$, and the remaining set of covariates is the same as in equation (1). The fitted values of $\hat{S}$ in equation (2) are then plugged into the original regression equation (1) in a standard two-stage least squares approach. Throughout the analysis, we cluster standard errors by player, the same level of variation of our instrument.

The main rationale behind the use of peers' yellow cards as instrument is that this proxies the level of 'aggressiveness' of teammates. This triggers the probability of clashes during training sessions or games and thus increases the probability of injury. On the other hand, this should not be directly related to individual wages. Yellow cards have the advantage of measuring the severity of the fouls and are exogenously assigned by the match referees.

We now discuss in more detail the relevance and validity of this instrument in our setting. Firstly, to be a relevant instrument, it should show some variation over time and across players that predicts the likelihood of injury. The fact that individual $i$ is excluded from the

\footnotetext{
${ }^{9}$ In the case of players with dual citizenship, we consider as a main citizenship, the corresponding national team for which the player opted to play.
} 
computation of the average yellow cards received by the team and the trading of players generates a large turnover of teammates both within (during the two market windows in a year) and between seasons. Importantly, the same is also true for managers. Their turnover generates variation in the team's attitude, according to their managerial strategy. As mentioned before, yellow cards are a measure of the 'aggressiveness' of teammates and are correlated to the probability of injuries through two different channels. On one hand, a more aggressive team might incur a higher risk due to their attitude towards the game. On the other hand, due to reciprocity, the opposing team might play in a tougher way in response, increasing the number of physical clashes and, consequently, the probability of injuries. This is corroborated by first-stage regressions shown in Table A. 2 in the Appendix, where we present the first-stage regressions on the full set of covariates, for several specifications. We observe a positive and significant association between the number of yellow card received and the probability of injuries. Thus, the mechanism suggested by the first-stage indicates that playing for a more aggressive team is associated with a higher number of days off, significant at $1 \%$ level, confirming the intuition behind the relevance of the instrument. Furthermore, at the bottom of Table A.2, we report the F-test results of whether the excluded instrument significantly differs from zero (Staiger and Stock, 1997). These values are above both the rough, but commonly used, rule of the thumb of 10 and the more formal cut-offs provided by Stock and Yogo (2005).

Lastly, we discuss the plausibility of the exclusion restriction implied by our instrument. One possible mechanism which might invalidate the use of yellow cards as an instrument is that a yellow card represents a proxy for an aggressive player's style, and this style of play could be rewarded in the labour market through a higher wage. However, the key to our instrument is that we use the average number of yellow cards received by the player's teammates rather than yellow cards received by the individual themself. Teammates' aggressiveness might affect the player's style of play through a 'peer effect', but it is unlikely to be correlated directly with their own wage. Moreover, it is important to note that our specifications include also team fixed effects and this allays concerns that the team's aggressiveness might lead to higher wages for all team members (including $i$ ). To provide further support to the validity of this argument, we also estimate the correlation between yellow cards received by teammates and measures of both sporting and economic performance of the club, the final ranking position and the average wage bill of the team. We find a very low correlation of 0.12 and 0.06 , respectively, and this supports the idea that team aggressiveness is likely to be poorly correlated with a club's economic and sporting performances.

\section{Model for contract renegotiation}

One advantage of using sports data for labour market analysis is the availability of information about the contract between the player and the team, which can be renegotiated at any point before it expires. There are two main reasons for renegotiating the player's contract. First, if the contract is close to expiry, the club might not want to risk losing a player without any monetary compensation. Second, the player may be traded to another club during one of the two transfer market periods, thus entailing the signing of a new contract. To assess the impact of the productivity shock due to injury on the probability of renegotiating the contract at the end of the season, we make use of a binary choice model. 
A linear probability model (LPM) is used to exploit the longitudinal nature of the data and the IV strategy, with fixed effects to control for individual time-invariant characteristics. We estimate the following equation:

$$
d_{i t}=\delta_{0}+\delta_{1} X_{i, t-1}+\delta_{2} P_{i, t-1}+\delta_{3} S_{i, t-1}+\delta_{4} \text { Season }_{t}+\delta_{5} \text { Team }_{j, t}+\eta_{i}+\vartheta_{i t}
$$

where $d_{i t}$ is a dichotomous variable assuming either value 1 if the contract between the player and the club has been renegotiated at the end of the season or value 0 if it had not. The covariate $S_{i, t-1}$ represents the incidence of the productivity shock through the number of days off due to the reported injury. The remaining covariates are the same as described in equation (1). Furthermore, to reduce concern about the endogeneity of the injury, we implement the IV strategy as explained above, using the 2SLS estimator and instrumenting the injury through the average value of the team's yellow cards, excluding those of the individual $i^{10}$.

\section{Results}

\section{Effects of injuries on wages}

Tables 4-6 show the results of the fixed effects model described in equation (1), with the logarithm of wage as the dependent variable. Table 4 shows the results for the full sample, Table 5 controls for muscular injuries and Table 6 shows results for a subsample in which muscular injuries are dropped. Column 1 of each table reports the results of the FE model, without team fixed effects and the control for the timing of the injury. Columns 2-3 include results with either team fixed effects or the timing of the injury. The results in column 4 account for both. Moreover, to make the economic interpretation of the coefficient of interest easier and more comparable, we present estimates of the impact of a 30-day change in the number of days off due to injury, in other words, for a month out of the game due to injury. Other covariate coefficients are presented for a change of one standard deviation, as reported in the summary statistics (Table 1). Since the dependent variable is in log format, the estimated coefficients report percentage variation in the net annual wage associated with a one standard deviation increase in the independent variable.

Table 4 shows a negative relationship between days off due to injury and the net wage. In particular, one-month of injury is associated with a reduction of about $2.5 \%$ in the wage for the following season. The size and significance of the coefficient remains the same when controlling for team fixed effects and it increases slightly when the timing of the injury is controlled for.

With respect to the other covariates, Table 4 shows that both indicators of performance and popularity are significant and have a positive effect on the annual net wage. In par-

\footnotetext{
${ }^{10}$ An alternative to the LPM is the fixed-effect (FE) logit model. Compared to the LPM, the FE logit gives a response probability that ranges from 0 to 1 . However, one drawback of the FE logit models is that the interpretation of the results is somewhat cumbersome, due to the problem of computing predicted probabilities of the outcome and the marginal or discrete effects when the fixed effect is unknown. We thus opted to include only LPM estimates However, we also perform estimates based on FE logit estimates which lead to qualitatively similar results (available upon request).
} 
TABLE 4

Effects of injury and other covariates on annual net (log)wage. Fixed effects estimates.

\begin{tabular}{lllll}
\hline & $(1)$ & $(2)$ & $(3)$ & $(4)$ \\
\hline Days-Off traum. & $-0.0250^{* *}$ & $-0.0250^{* *}$ & $-0.0283^{* *}$ & $-0.0284^{* *}$ \\
& 0.0118 & 0.0118 & 0.0118 & 0.0118 \\
Age & $0.8971^{* * *}$ & $0.9031^{* * *}$ & $0.8796^{* * *}$ & $0.8856^{* * *}$ \\
& 0.0639 & 0.0640 & 0.0640 & 0.0641 \\
Age sq. & $-0.0150^{* * *}$ & $-0.0151^{* * *}$ & $-0.0148^{* * *}$ & $-0.0149^{* * *}$ \\
& 0.0011 & $0.0011^{* *}$ & 0.0011 & 0.0011 \\
Goal & $0.0491^{* * *}$ & $0.0486^{* *}$ & $0.0507^{* * *}$ & $0.0502^{* * *}$ \\
& 0.0190 & 0.0190 & 0.0189 & 0.0189 \\
Assist & -0.0024 & -0.0031 & -0.0045 & -0.0053 \\
& 0.0144 & 0.0144 & 0.0144 & 0.0144 \\
Grade & 0.0181 & 0.0188 & 0.0176 & 0.0184 \\
& 0.0149 & 0.0149 & 0.0148 & 0.0148 \\
Popularity & $0.0321^{* *}$ & $0.0330^{* *}$ & $0.0315^{* *}$ & $0.0325^{* *}$ \\
& 0.0160 & 0.0160 & 0.0159 & 0.0159 \\
Injury timing & No & No & Yes & Yes \\
Team FE & No & Yes & No & Yes \\
$N$ & 1197 & 1197 & 1197 & 1197 \\
\hline
\end{tabular}

Notes: ***,**, indicate significance at $1 \%, 5 \%$ and $10 \%$, respectively.

The model includes the full set of controls: dummy for the team captain; number of caps in the league during the season; number of senior national team caps during the season; number of national under-21 team caps during the season; dummy for the reoccurrence of the same injury; season fixed effects. Standard Errors in italics.

ticular, in the baseline model (Column 1), a one standard deviation increase in goals and popularity affects the following season's wage by about $4.9 \%$ and $3.2 \%$, respectively. Coefficients remain virtually unaltered when accounting for team fixed effects and the timing of the injury.

These results are robust to different model specifications, when controlling for muscular injuries (Table 5) or dropping them from the sample (Table 6). Indeed, in Table 5, the coefficient of days off due to muscular injuries is not statistically significant. This result supports the intuition that the shock effect on wages is due to those injuries that have an underlying random component, such as the traumatic types of injury.

Interestingly, there is a larger difference between coefficients when the timing of the injury is included. These results indicate that, during the wage bargaining process, variation across the season should be accounted for. In particular, some months might be associated with worse weather conditions or with a larger number of matches played due to the calendar of fixtures, which exposes players to higher stress in some periods of the season.

The results for the FE-IV estimation on the full set of controls are shown in Table 7. Making use of the teammates' yellow cards as an instrument, results in a significant increase in the coefficient of the days off variable. A one-month injury has a more negative effect on the wage, by about $12 \%$; the coefficient is statistically significant at the $5 \%$ level. 
TABLE 5

Effects of injury and other covariates on annual net (log)wage. Fixed effects estimates. Days off due to muscular injury as control.

\begin{tabular}{lcccc}
\hline & $(1)$ & $(2)$ & $(3)$ & $(4)$ \\
\hline Days-off traum. & $-0.0230^{*}$ & $-0.0230^{*}$ & $-0.0276^{* *}$ & $-0.0277^{* *}$ \\
& 0.0120 & 0.0120 & 0.0121 & 0.0121 \\
Days-off musc. & 0.0007 & 0.0007 & 0.0002 & 0.0002 \\
& 0.0008 & 0.0008 & 0.0008 & 0.0008 \\
Age & $0.8924^{* * *}$ & $0.8984^{* * *}$ & $0.8786^{* * *}$ & $0.8847^{* * *}$ \\
& 0.0642 & 0.0643 & 0.0642 & 0.0643 \\
Age sq. & $-0.0149^{* * *}$ & $-0.0150^{* * *}$ & $-0.0148^{* * *}$ & $-0.0149^{* * *}$ \\
& 0.0011 & 0.0011 & 0.0011 & 0.0011 \\
Goal & $0.0487^{* *}$ & $0.0482^{* *}$ & $0.0505^{* * *}$ & $0.0501^{* * *}$ \\
& 0.0190 & 0.0190 & 0.0189 & 0.0189 \\
Assist & -0.0029 & -0.0036 & -0.0046 & -0.0054 \\
& 0.0145 & 0.0145 & 0.0144 & 0.0144 \\
Grade & 0.0175 & 0.0183 & 0.0175 & 0.0182 \\
& 0.0149 & 0.0149 & 0.0149 & 0.0149 \\
Popularity & $0.0321^{* *}$ & $0.0331^{* *}$ & $0.0315^{* *}$ & $0.0325^{* *}$ \\
& 0.0160 & 0.0160 & 0.0159 & 0.0159 \\
Injury timing & No & No & Yes & Yes \\
Team FE & No & Yes & No & Yes \\
$N$ & 1197 & 1197 & 1197 & 1197 \\
\hline
\end{tabular}

Notes: $* * *, * *, *$ indicate significance at $1 \%, 5 \%$ and $10 \%$, respectively.

The model includes the full set of controls: dummy for the team captain; number of caps in the league during the season; number of senior national team caps during the season; number of national under-21 team caps during the season; dummy for the reoccurrence of the same injury; season fixed effects. Standard Errors in italics.

With respect to the other covariates, a one standard deviation increase in goals and popularity leads to a positive effect on the annual net wage of about $5.4 \%$ and $3.4 \%$, respectively. The effect is slightly higher than in the FE model and the coefficients concerning goals are still significant at the $5 \%$ level, while for popularity they drop to the $10 \%$ level, showing less spread among the different model specifications, when team fixed effects and/or the timing of the injury are controlled for.

Moreover, results show a nonlinear relationship between age and wages. In particular, wages increase with age due to the cumulated experience and knowledge of the game until a turning point where these are overcome by the progressive loss of physical skills. We estimate this turning point to be at around 32 years old, higher than in the earlier evidence (Lucifora and Simmons, 2003) and consistent with the evidence of the elongation of players' careers observed in the last 15 years.

Table 8 reports estimates that exclude the performance-related covariates. This specification helps to disentangle the effect of the injury on the wage into a direct effect and an indirect one, which is mediated by performance. It is interesting to notice that when the model does not control for performance, the coefficient of the days off increases by around $1 \%$, across the different specifications. Thus, it is possible to argue that the effect of the injury is mediated through performance, due to reduced current producti- 
TABLE 6

Effects of injury and other covariates on annual net (log)wage. Fixed effects estimates. Days off due to muscular injury dropped.

\begin{tabular}{lcccc}
\hline & $(1)$ & $(2)$ & $(3)$ & $(4)$ \\
\hline Days-off traum. & $-0.0217^{*}$ & $-0.0218^{*}$ & $-0.0281^{* *}$ & $-0.0283^{* *}$ \\
& 0.0132 & 0.0132 & 0.0136 & 0.0137 \\
Age & $0.8051^{* * *}$ & $0.8059^{* * *}$ & $0.8000^{* * *}$ & $0.8015^{* * *}$ \\
& 0.0761 & 0.0765 & 0.0760 & 0.0764 \\
Age sq. & $-0.0134^{* * *}$ & $-0.0134^{* * *}$ & $-0.0134^{* * *}$ & $-0.0134^{* * *}$ \\
& 0.0013 & 0.0013 & 0.0013 & 0.0013 \\
Goal & $0.0586^{* *}$ & $0.0586^{* *}$ & $0.0572^{* *}$ & $0.0571^{* *}$ \\
& 0.0248 & 0.0249 & 0.0248 & 0.0248 \\
Assist & 0.0097 & 0.0096 & 0.0070 & 0.0068 \\
& 0.0189 & 0.0190 & 0.0189 & 0.0190 \\
Grade & $0.0397^{* *}$ & $0.0398^{* *}$ & $0.0401^{* *}$ & $0.0403^{* *}$ \\
& 0.0191 & 0.0192 & 0.0191 & 0.0191 \\
Popularity & 0.0329 & 0.0331 & 0.0321 & 0.0324 \\
& 0.0204 & 0.0205 & 0.0204 & 0.0205 \\
Injury timing & No & No & Yes & Yes \\
Team FE & No & Yes & No & Yes \\
$N$ & 848 & 848 & 848 & 848 \\
\hline
\end{tabular}

Notes: $* * *, * *, *$ indicate significance at $1 \%, 5 \%$ and $10 \%$, respectively.

The model includes the full set of controls: dummy for the team captain; number of caps in the league during the season; number of senior national team caps during the season; number of national under-21 team caps during the season; dummy for the reoccurrence of the same injury; season fixed effects. Standard Errors in italics.

vity, by only a small amount. Indeed, these results can be seen in a framework of human capital depreciation as showing that during the bargaining process the club is willing to offer a lower amount to the player for precautionary reasons rather than because of the negative effect of the injury on the individual's current productivity. In order to explore this hypothesis, we regress a set of future productivity measures along with a dummy for future injuries on the lagged values of days off $(t-1)$. Results are reported in Table A.3. The estimates suggest that the injuries are predictive of a future drop in both the number of minutes played $(-11 \%)$ and the quality of the performance (i.e. grade and assists). Consistent with previous findings, under the assumption of rational clubs and players, this supports the idea that serious injuries lead to lower future productivity. Interestingly, injuries at time $t-1$ are not significantly associated with the probability of future injuries (at time t). This is consistent with the intrinsic randomness of traumatic injuries.

When comparing these results with the corresponding OLS estimates presented above, and assuming the former to be unbiased, we observe that the FE-IV results are somewhat larger in absolute value. As is well known, the IV strategy only allows us to estimate a local average treatment effect (LATE), which is the effect among the subgroup of players for whom a longer absence due to injury is induced because of their teammates' aggressive style of play reflected in the yellow cards they received. 
TABLE 7

Effects of injury and other covariates on annual net (log)wage. Fixed effects-IV estimates.

\begin{tabular}{lcccc}
\hline & $(1)$ & $(2)$ & $(3)$ & $(4)$ \\
\hline Days-off & $-0.1211^{* *}$ & $-0.1204^{* *}$ & $-0.1258^{* *}$ & $-0.1250^{* *}$ \\
Age & 0.0563 & 0.0558 & 0.0598 & 0.0592 \\
& $0.9795^{* * *}$ & $0.9861^{* * *}$ & $0.9776^{* * *}$ & $0.9839^{* * *}$ \\
Age sq. & 0.0856 & 0.0857 & 0.0859 & 0.0859 \\
& $-0.0161^{* * *}$ & $-0.0161^{* * *}$ & $-0.0160^{* * *}$ & $-0.0161^{* * *}$ \\
Goal & 0.0014 & 0.0014 & 0.0014 & 0.0014 \\
& $0.0538^{* *}$ & $0.0540^{* *}$ & $0.0533^{* *}$ & $0.0535^{* *}$ \\
Assist & 0.0214 & 0.0214 & 0.0216 & 0.0216 \\
& 0.0043 & 0.0038 & 0.0033 & 0.0027 \\
Grade & 0.0167 & 0.0167 & 0.0169 & 0.0168 \\
& 0.0276 & $0.0286^{*}$ & 0.0282 & $0.0293^{*}$ \\
Popularity & 0.0169 & 0.0169 & 0.0172 & 0.0172 \\
& $0.0345^{*}$ & $0.0353^{*}$ & $0.0351^{*}$ & $0.0359^{*}$ \\
Injury timing & 0.0183 & 0.0183 & 0.0185 & 0.0185 \\
Team FE & No & No & Yes & Yes \\
$N$ & No & Yes & No & Yes \\
First Stage F-test & 1099 & 1099 & 1099 & 1099 \\
\hline
\end{tabular}

Notes: $* * *, * *, *$ indicate significance at $1 \%, 5 \%$ and $10 \%$, respectively.

The model includes the full set of controls: dummy for the team captain; number of caps in the league during the season; number of senior national team caps during the season; number of national under-21 team caps during the season; dummy for the reoccurrence of the same injury; season fixed effects. Standard Errors in italics.

\section{TABLE 8}

Effects of injury and other covariates on annual net (log)wage. Fixed effects-IV results. Performance not controlled for.

\begin{tabular}{lcccc}
\hline & $(1)$ & $(2)$ & $(3)$ & $(4)$ \\
\hline Days-off & $-0.1303^{* *}$ & $-0.1309^{* *}$ & $-0.1362^{* *}$ & $-0.1367^{* *}$ \\
& 0.0581 & 0.0578 & 0.0620 & 0.0615 \\
Age & $1.0168^{* * *}$ & $1.0246^{* * *}$ & $1.0141^{* * *}$ & $1.0217^{* * *}$ \\
& 0.0882 & 0.0884 & 0.0885 & 0.0887 \\
Age sq. & $-0.0167^{* * *}$ & $-0.0168^{* * *}$ & $-0.0167^{* * *}$ & $-0.0168^{* * *}$ \\
& 0.0014 & 0.0014 & 0.0015 & 0.0015 \\
Popularity & $0.0334^{*}$ & $0.0343^{*}$ & $0.0341^{*}$ & $0.0350^{*}$ \\
& 0.0186 & 0.0186 & 0.0188 & 0.0188 \\
Injury timing & $\mathrm{No}$ & $\mathrm{No}$ & Yes & Yes \\
Team FE & $\mathrm{No}$ & $\mathrm{Yes}$ & $\mathrm{No}$ & Yes \\
$N$ & 1099 & 1099 & 1099 & 1099 \\
First Stage F-test & 19.67 & 19.80 & 17.74 & 17.97 \\
\hline
\end{tabular}

Notes: $* * *, * *, *$ indicate significance at $1 \%, 5 \%$ and $10 \%$, respectively.

The model includes the full set of controls: dummy for the team captain; number of caps in the league during the season; number of senior national team caps during the season; number of national under-21 team caps during the season; dummy for the reoccurrence of the same injury; season fixed effects. Standard Errors in italics. 
TABLE 9

Effects of injury and other covariates on renegotiation. Linear probability model.

\begin{tabular}{lcccr}
\hline \multirow{5}{*}{ Linear probability model } \\
\cline { 2 - 5 } & $(1)$ & $(2)$ & $(3)$ & \multicolumn{1}{l}{$(4)$} \\
\hline Days-off & 0.079 & 0.079 & 0.054 & 0.057 \\
& 0.073 & 0.073 & 0.075 & 0.075 \\
Age & 0.052 & 0.046 & 0.042 & 0.036 \\
& 0.111 & 0.103 & 0.099 & 0.100 \\
Age sq. & 0.001 & 0.002 & 0.001 & 0.002 \\
& 0.001 & 0.002 & 0.002 & 0.002 \\
Caps & $0.008^{*}$ & $0.009^{*}$ & $0.008^{*}$ & $0.008^{*}$ \\
& 0.005 & 0.005 & 0.005 & 0.005 \\
Goal & -0.037 & -0.037 & -0.039 & -0.039 \\
& 0.028 & 0.027 & 0.026 & 0.026 \\
Assist & 0.002 & 0.002 & -0.003 & -0.003 \\
& 0.022 & 0.022 & 0.022 & 0.022 \\
Grade & 0.020 & 0.020 & 0.024 & 0.023 \\
& 0.022 & 0.021 & 0.021 & 0.021 \\
Popularity & $-0.040^{*}$ & $-0.041^{*}$ & $-0.037^{*}$ & $-0.038^{*}$ \\
& 0.024 & 0.021 & 0.020 & 0.020 \\
Injury timing & No & No & Yes & Yes \\
Team FE & No & Yes & No & Yes \\
$N$ & 1.099 & 1.099 & 1.099 & 1.099 \\
\hline
\end{tabular}

Notes: ${ }^{* * *},{ }^{* *},{ }^{*}$ indicate significance at $1 \%, 5 \%$ and $10 \%$, respectively.

The model includes the full set of controls: dummy for the team captain; number of caps in the league during the season; number of senior national team caps during the season; number of national under-21 team caps during the season; dummy for the reoccurrence of the same injury; season fixed effects. Standard Errors in italics.

\section{Effects of injuries on contract renegotiation}

Tables 9 and 10 show the results of the models of wage renegotiation with and without controlling for performance, respectively. Table 10 thus includes in the sample also those individuals whose performance was not measurable due to the fact that they did not play any official match, because of season-long injuries. Columns $1-4$ of both tables report estimates of the linear probability model described in equation (3).

Table 9 shows that injuries are positively associated with the probability of renegotiating the contract at the end of the season. The coefficient is not statistically significant at conventional levels. However, when including in the sample those with season-long injuries, as in Table 10, the injury effect is estimated to be negative and statistically significant. Specifically, a 30-day injury is found to increase the probability of renegotiating the contract by approximately $9.8 \%$. This result is likely to be led especially by those with a low residual length of their contract who have a higher probability of wage renegotiation with the same or another club.

Thus, an interesting dynamic emerges from these results. Injury is found to have a significant effect on the probability of renegotiation of the contract. This effect is even 
TABLE 10

Effects of injury and other covariates on renegotiation. Linear probability model. Performance not controlled for.

\begin{tabular}{lcccc}
\hline & $(1)$ & $(2)$ & $(3)$ & $(4)$ \\
\hline Days-off & $0.098^{*}$ & $0.104^{*}$ & 0.069 & 0.075 \\
& 0.046 & 0.047 & 0.049 & 0.050 \\
Age & $0.200^{* *}$ & $0.189^{* *}$ & $0.189^{* *}$ & $0.179^{* *}$ \\
& 0.083 & 0.079 & 0.074 & 0.076 \\
Age sq. & -0.001 & -0.001 & -0.001 & -0.001 \\
& 0.001 & 0.001 & 0.001 & 0.001 \\
Caps & $0.010^{* * *}$ & $0.010^{* * *}$ & $0.009^{* * *}$ & $0.010^{* * *}$ \\
& 0.002 & 0.001 & 0.001 & 0.002 \\
Popularity & $-0.031^{*}$ & $-0.032^{* *}$ & $-0.028^{* *}$ & $-0.029^{* *}$ \\
& 0.017 & 0.014 & 0.014 & 0.014 \\
Injury timing & No & No & Yes & Yes \\
Team FE & No & Yes & No & Yes \\
$N$ & 1527 & 1527 & 1527 & 1527 \\
\hline
\end{tabular}

Notes: $* * *, * *, *$ indicate significance at $1 \%, 5 \%$ and $10 \%$, respectively. The model includes the full set of controls: dummy for the team captain; number of caps in the league during the season; number of senior national team caps during the season; number of national under-21 team caps during the season; dummy for the reoccurrence of the same injury; season fixed effects. Standard Errors in italics.

more prominent if the injury resulted in worse performances or persisted throughout the entire season, preventing a player from taking part in any official match. It follows that players with reduced productivity may have to accept either a lower paid contract or migrate to another club at the end of the season.

Every additional 90 minutes played increases the probability of renegotiating the contract by about 0.85 points. Essentially, the clubs are interested in extending the contracts of those players who offer a higher reliability in terms of both physical and tactical integrity and experience, cumulated through the larger number of matches played.

Interestingly, an increase in popularity is negatively associated with contract renegotiation. This result is indicative of a well-known dynamic in the football market. In fact, when a player's popularity increases they have an increased incentive to delay the contract renegotiation with their own club with the aim of arriving as close as possible to the expiration date in order to threaten the club into offering them a higher wage so as not to lose the player without any monetary compensation at the end of their contract. Furthermore, a popular player represents an important asset for the club in terms of merchandising and image rights. Hence, the bargaining process becomes much more complex and the timing of the contract renegotiation plays a central role.

\section{Robustness checks}

To check the robustness of these findings, we perform a number of sensitivity analyses. Firstly, an alternative measure of injury namely the total number of official league matches in which the player was reported as 'not available due to injury' is used to check whether 
TABLE 11

Robustness check: effects of injury and other covariates on annual net (log)wage. Alternative health shock's measure. Fixed effects-IV estimates.

\begin{tabular}{lcccc}
\hline & $(1)$ & $(2)$ & $(3)$ & $(4)$ \\
\hline Matches-off & $-0.0282^{* *}$ & $-0.0294^{* *}$ & $-0.0289^{* *}$ & $-0.0301^{* *}$ \\
& 0.0134 & 0.0141 & 0.0140 & 0.0147 \\
Age & $1.0003^{* * *}$ & $1.0117^{* * *}$ & $0.9996^{* * *}$ & $1.0109^{* * *}$ \\
& 0.0930 & 0.0956 & 0.0933 & 0.0960 \\
Age sq. & $-0.0162^{* * *}$ & $-0.0164^{* * *}$ & $-0.0162^{* * *}$ & $-0.0163^{* * *}$ \\
& 0.0015 & 0.0015 & 0.0015 & 0.0015 \\
Goal & $0.0472^{* *}$ & $0.0467^{* *}$ & $0.0467^{* *}$ & $0.0462^{* *}$ \\
& 0.0220 & 0.0223 & 0.0222 & 0.0225 \\
Assist & 0.0098 & 0.0096 & 0.0093 & 0.0090 \\
& 0.0177 & 0.0179 & 0.0177 & 0.0179 \\
Grade & $0.0355^{*}$ & $0.0369^{* *}$ & $0.0361^{*}$ & $0.0376^{* *}$ \\
& 0.0184 & 0.0187 & 0.0187 & 0.0190 \\
Popularity & $0.0313^{*}$ & $0.0322^{*}$ & $0.0316^{*}$ & $0.0326^{*}$ \\
& 0.0187 & 0.0189 & 0.0188 & 0.0190 \\
Injury timing & No & No & Yes & Yes \\
Team FE & No & Yes & No & Yes \\
$N$ & 1099 & 1099 & 1099 & 1099 \\
First Stage F-test & 19.08 & 17.59 & 17.72 & 16.56 \\
\hline
\end{tabular}

Notes: $* * * * * * *$ indicate significance at $1 \%, 5 \%$ and $10 \%$, respectively.

The model includes the full set of controls: dummy for the team captain; number of caps in the league during the season; number of senior national team caps during the season; number of national under-21 team caps during the season; dummy for the reoccurrence of the same injury; season fixed effects. Standard Errors in italics.

the results are confirmed. It may be argued that the maximum number of days off is specific to the form of injury and that an injury may be less consequential in periods of the year where it does not overlap with any official matches. Nevertheless, the channel through which the club decides to offer a lower wage might be based on the rate of participation of the player in official matches. The estimates, reported in Table 11, show that the results are robust when based on this alternative shock measure. In fact, every additional match missed negatively affects the wage for the following season by approximately $2.8 \%$. This result is consistent with the main results in both sign and magnitude. In fact, on average, a Serie A club has about five matches scheduled each month, making this result proportional to the baseline one, in which 30-day variations in the number of days off were considered.

Secondly, we test whether the dynamics of the model are correctly specified. In fact, under multi-year contracts the effect on the wage might have been determined by a shock that occurred in a previous season compared to the one of the baseline model (i.e. $t-2$ or $\mathrm{t}-3$ ). Thus, we run the model including the lagged values of days off up to three seasons before. Table 12 shows that even though the number of days off in earlier seasons is negatively associated with the net wage, the coefficients are not statistically significant at conventional levels, reinforcing the idea that the negative effect is caused by the injury occurring in the previous season with respect to the eventual contract renegoti- 
TABLE 12

Robustness check: effects of injury and other covariates on annual net (log)wage. Lagged health shock's values included. Fixed effects estimates.

\begin{tabular}{lcccc}
\hline & $(1)$ & $(2)$ & $(3)$ & $(4)$ \\
\hline Age & $0.9356^{* * *}$ & $0.9371^{* * *}$ & $0.9253^{* * *}$ & $0.9280^{* * *}$ \\
& 0.1319 & 0.1313 & 0.1335 & 0.1325 \\
Age sq. & $-0.0155^{* * *}$ & $-0.0155^{* * *}$ & $-0.0153^{* * *}$ & $-0.0154^{* * *}$ \\
& 0.0022 & 0.0022 & 0.0022 & 0.0022 \\
Goal & $0.0451^{*}$ & $0.0453^{* *}$ & $0.0449^{* *}$ & $0.0454^{* *}$ \\
& 0.0256 & 0.0256 & 0.0251 & 0.0251 \\
Assist & 0.0266 & 0.0265 & 0.0252 & 0.0250 \\
& 0.0172 & 0.0170 & 0.0171 & 0.0170 \\
Grade & $0.0446^{* *}$ & $0.0446^{* *}$ & $0.0449^{* *}$ & $0.0449^{* *}$ \\
& 0.0206 & 0.0206 & 0.0204 & 0.0204 \\
Popularity & $0.0583^{*}$ & $0.0584^{*}$ & $0.0565^{*}$ & $0.0567^{*}$ \\
& 0.0336 & 0.0336 & 0.0330 & 0.0331 \\
Days-off & $-0.0333^{*}$ & $-0.0331^{*}$ & $-0.0348^{*}$ & $-0.0346^{*}$ \\
& 0.0186 & 0.0185 & 0.0187 & 0.0186 \\
Days-off & -0.0220 & -0.0220 & -0.0201 & -0.0201 \\
& 0.0215 & 0.0215 & 0.0215 & 0.0213 \\
Days-off & -0.0365 & -0.0364 & -0.0351 & -0.0349 \\
& 0.0242 & 0.0242 & 0.0241 & 0.0241 \\
Injury timing & No & No & Yes & Yes \\
Team FE & No & Yes & No & Yes \\
$N$ & 664 & 664 & 664 & 664 \\
\hline
\end{tabular}

Notes: ***,**, $*$ indicate significance at $1 \%, 5 \%$ and $10 \%$, respectively.

The model includes the full set of controls: dummy for the team captain; number of caps in the league during the season; number of senior national team caps during the season; number of national under-21 team caps during the season; dummy for the reoccurrence of the same injury; season fixed effects. Standard Errors in italics.

ation. This result is in line with findings from other sports settings (Healy, 2008) and highlights how economic agents access the most salient information when making decisions.

Thirdly, to check the robustness of the hypothesis about the existence of a difference between the direct effect of the injury on the outcome and the indirect one mediated through performance, we estimate performance measures that are not affected by injury. In particular, we proxy the non-injury affected performance by the OLS residuals of the regression of the performance's measures (i.e. grade, goal and assist) on the number of days off, while controlling for age and seasonal fixed effects. Then we include the injurypurged variables as covariates in the FE-IV estimation. The results, reported in Table 13, show that the magnitude and the sign of the impact remains unaltered compared to the baseline model. Interestingly, in this specification, the grade of the overall performance becomes statistically significant: a one standard deviation increase in the injury-purged performance positively affects the net wage of the following year by approximately $4.7 \%$. This strengthens the evidence in support of the existence of both a direct and an indirect effect of injuries. 
TABLE 13

Robustness check: Effects of injury and other covariates on annual net (log)wage. Injury-purged variables included. Fixed effects estimates.

\begin{tabular}{lcccc}
\hline & $(1)$ & $(2)$ & $(3)$ & $(4)$ \\
\hline Days-off & $-0.1218^{* *}$ & $-0.1207^{* *}$ & $-0.1258^{* *}$ & $-0.1246^{* *}$ \\
& 0.0544 & 0.0536 & 0.0574 & 0.0564 \\
Age & $0.9777^{* * *}$ & $0.9841^{* * *}$ & $0.9755^{* * *}$ & $0.9817^{* * *}$ \\
& 0.0818 & 0.0817 & 0.0819 & 0.0817 \\
Age sq. & $-0.0159^{* * *}$ & $-0.0160^{* * *}$ & $-0.0159^{* * *}$ & $-0.0160^{* * *}$ \\
& 0.0013 & 0.0013 & 0.0014 & 0.0014 \\
Goal_purged & $0.1150^{* * *}$ & $0.1150^{* * *}$ & $0.1149^{* * *}$ & $0.1148^{* * *}$ \\
& 0.0324 & 0.0322 & 0.0326 & 0.0323 \\
Assist_purged & $0.0826^{* * *}$ & $0.0820^{* * *}$ & $0.0821^{* * *}$ & $0.0815^{* * *}$ \\
& 0.0297 & 0.0295 & 0.0297 & 0.0295 \\
Grade_purged & $0.0467^{* *}$ & $0.0476^{* *}$ & $0.0478^{* *}$ & $0.0486^{* *}$ \\
& 0.0202 & 0.0201 & 0.0208 & 0.0206 \\
Popularity & $0.0337^{*}$ & $0.0346^{*}$ & $0.0342^{*}$ & $0.0351^{*}$ \\
& 0.0180 & 0.0179 & 0.0181 & 0.0181 \\
Injury timing & No & No & Yes & Yes \\
Team FE & No & Yes & No & Yes \\
$N$ & 1099 & 1099 & 1099 & 1099 \\
First Stage F-test & 21.46 & 21.98 & 19.77 & 20.34 \\
\hline
\end{tabular}

Notes: $* * * * * * *$ indicate significance at $1 \%, 5 \%$ and $10 \%$, respectively.

Covariates concerning purged Goal, Assist and Grade refers to OLS residuals of the covariate regression on days off, age, age sq. and season fixed effects. The model includes the full set of controls: dummy for the team captain; number of caps in the league during the season; number of senior national team caps during the season; number of national under-21 team caps during the season; dummy for the reoccurrence of the same injury; season fixed effects. Standard Errors in italics.

\section{Conclusions}

This paper exploits data from professional football in Italy to estimate the effect of productivity shocks due to injuries on labour market outcomes. Using a unique longitudinal data set created by combining information from several sources about the characteristics of the universe of football players of the Italian Serie A, followed from 2010 to 2015, our analysis makes a number of substantial contributions to the literature on the labour market consequences of productivity shocks in the context of a group of high-earning individuals. The working super-rich phenomenon started to rise considerably from the 1970s in all developed countries attracting the interest of many scholars (Atkinson et al., 2011). Previous analyses have focused on several dimensions of this phenomenon, including the determinants of the high earnings and the effects on overall inequality. However, to the best of our knowledge, no previous studies have focused on the effect of productivity shocks due to health on their earnings.

We exploit the exogenous nature of traumatic injuries and the availability of panel data to retrieve causal estimates of the effect of the shock on labour market outcomes and we also employ an instrumental variable strategy that uses the average number of yellow cards received by the team as an instrument to further deal with time-varying unobserved hetero- 
geneity. This is a rare feature of studies analysing the relationship between health shocks and outcomes, which are often based on cross-sectional survey data. In these settings, it is generally hard to deal with the endogenous relationship between health shocks and labour market outcomes.

Professional sports data provides detailed measures of worker's productivity. This is useful in order to disentangle the main channels through which health shock affects labour market outcomes in our setting. Analysis of the effect of injuries on the probability of renegotiation has direct implications for the football industry and in particular on the fixing of the optimal length of contract from both player and club perspectives.

The main findings of our paper can be summarized as follows. Firstly, we find that injuries have a strong negative effect on the wages of the professional football players of the Italian Serie A. In particular, having a 30-day injury reduces the wage of the following year by approximately $12 \%$. Secondly, we find that only a residual part of the negative effect could be explained through the reduced current performance of the players after the injury. The results suggest that the largest part of the coefficient is explained by a direct effect of the injury on the outcome. This result can be explained in a framework of human capital depreciation. The club has an incentive to offer a lower wage for precautionary reasons, supposing that players who experienced a severe injury might incur lower productivity in the future. Indeed, we show that the injuries are predictive of a future drop in a number of productivity measures. Thus, the club insures itself against this risk by reducing the fixed share of the wage, which is independent of match performances.

Furthermore, we find that the effect of the injury on the probability of renegotiating the contract at the end of the season increases with its severity. In fact, different model specifications show that having a season-long injury increases the probability of wage renegotiation with the same club or another one by about $10 \%$. This result suggests that the effect is explained by both the detrimental effect of the injury on performance and the precluded participation of the player in official matches. Finally, in line with the theoretical and empirical literature about super-earnings, we find that performance and popularity play an important role in explaining the wages of the 'working super-rich'.

Overall, these findings suggest that this group of the working super-rich are negatively affected by productivity shocks but with interesting peculiarities with respect to 'ordinary workers' First, the magnitude of the impact of a shock on working super-rich's income seems to be significantly larger than the effect on other workers. For instance, Halla and Zweimüller (2013) find an income loss of about 2-3\% among workers who incur accidents when commuting in Austria, while Garcia-Gómez et al. (2013) report a 5\% loss of personal income following acute hospital admission in the Netherlands. We find instead a wage penalization of $12 \%$ for an injury of only 30 days. Thus, the exposure to the injury seems to have more dramatic economic consequences for super-rich workers and the high salaries they receive are likely to incorporate a premium against the high costs associated with injuries Somewhat related, our results on the effect of injuries on contract renegotiation suggest that the length of a player's contract acts as an implicit risk-sharing mechanism between the player and the club against the risk of injury. This might have some interesting implications for the football industry for fixing the optimal length of the player's contract. Indeed, on one hand, a longer contract insures the player against the risk of injury, but 
imposes on the club the risk of paying an injured player. On the other hand, a shorter contract shifts the risk to the player but increases his bargaining power since he may threaten the club with accepting a better deal from another team (Blair, 2012). This suggests that both clubs and players are likely to face this trade-off when negotiating the length of contracts. This is an area for further exploration in which the preferences for risk of both agents are likely to play a substantial role.

The precautionary reasons underlying the wage penalization represent a substantial difference with respect to the effects of shock in other parts of the income distribution. This might be partly because the player's performance is largely based on physical ability, which might raise concerns around their future productivity. However, despite the obvious difference with other categories of jobs which instead rely more heavily on mental ability, our results may apply to other categories of super-rich whose rewards reflect competitive performance and popularity with the public. As pointed out by Mange and Philips (2016), many superstar professions share the tournament structure and short career duration evident in leading sport leagues such as the MLB. This also applies to Italian Serie A which is characterized by frequent contract renegotiations and high job turnover. More importantly, similar to many superstar professions, such as finance, CEOs and other highly paid professionals, professional sport careers are subject to a fierce competition and they generally involve a trade-off between high rewards for those few who reach the top and high attrition on the way up the ladder (Mange and Philips, 2016). Our analysis may offer a significant contribution to understand how productivity shocks affect labour market prospects in these superstar professions. Further research might investigate whether the patterns observed in our setting apply also to other categories of workers involved in less-physically demanding jobs.

\section{Appendix}

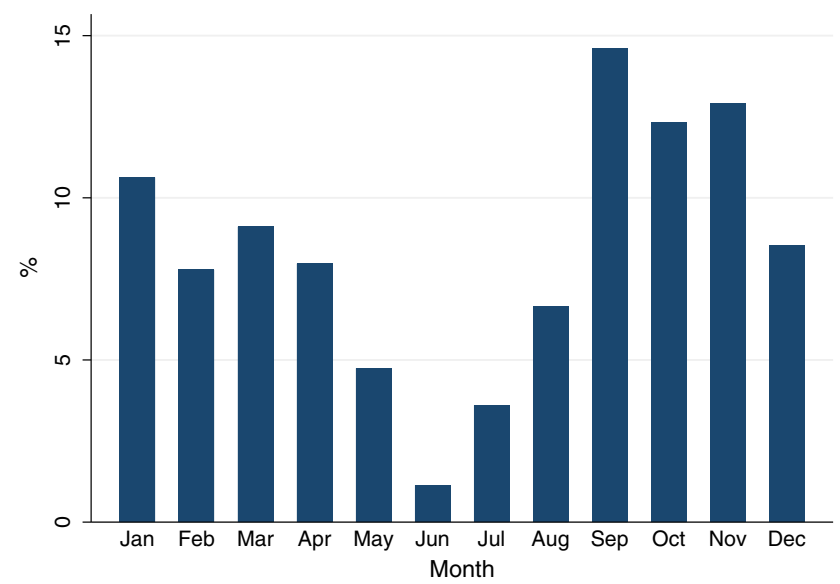

Figure A.1. Injuries percentage by month 
TABLE A.1

Teams' characteristics. Summary statistics and percentile distribution.

\begin{tabular}{llrrrr}
\hline & Wage expense & Net sales & \multicolumn{1}{c}{ EBT } & Ticketing & Television \\
\hline Mean & 19,656 & 90,720 & $-8,630$ & 10,838 & 53,341 \\
SD & 13,519 & 68,682 & 29,247 & 10,511 & 35,240 \\
min & 6,9 & 22,450 & $-93,767$ & 1,516 & 7,610 \\
p10 & 7,85 & 36,880 & $-45,919$ & 2,213 & 25,164 \\
p25 & 9,1 & 42,834 & $-14,040$ & 3880 & 29,870 \\
p50 & 13 & 56,312 & $-1,745$ & 5,014 & 34,499 \\
p75 & 28 & 116,446 & 3,636 & 15,134 & 70,744 \\
p90 & 42,95 & 212,419 & 12,438 & 31,017 & 115,010 \\
p99 & 47,6 & 272,404 & 84,582 & 38,051 & 163,478 \\
max & 47,6 & 272,404 & 84,582 & 38,051 & 163,478 \\
\hline
\end{tabular}

Notes: ${ }^{\text {a }}$ Values expressed in thousands of Euros

TABLE A. 2

First stage regressions.

\begin{tabular}{|c|c|c|c|c|}
\hline & $\begin{array}{l}\text { (1) } \\
\text { Days-off }\end{array}$ & $\begin{array}{l}\text { (2) } \\
\text { Days-off }\end{array}$ & $\begin{array}{l}\text { (3) } \\
\text { Days-off }\end{array}$ & $\begin{array}{l}\text { (4) } \\
\text { Days-off }\end{array}$ \\
\hline \multirow[t]{2}{*}{ Age } & $0.7763 * * *$ & $0.7770 * * *$ & $0.7214^{* *}$ & $0.7220 * *$ \\
\hline & 0.2963 & 0.2997 & 0.2947 & 0.2981 \\
\hline \multirow[t]{2}{*}{ Age sq. } & $-0.0100 * *$ & $-0.0100^{*}$ & $-0.0093 * *$ & $-0.0093 * *$ \\
\hline & 0.0051 & 0.0051 & 0.0050 & 0.0051 \\
\hline \multirow[t]{2}{*}{ Under 21} & -0.0252 & -0.0272 & -0.0256 & -0.0278 \\
\hline & 0.0472 & 0.0477 & 0.0467 & 0.0472 \\
\hline \multirow[t]{2}{*}{ International } & 0.0096 & 0.0098 & 0.0100 & 0.0101 \\
\hline & 0.0157 & 0.0159 & 0.0154 & 0.0156 \\
\hline \multirow[t]{2}{*}{ Captain } & -0.1979 & -0.1936 & -0.2266 & -0.2223 \\
\hline & 0.3099 & 0.3096 & 0.3149 & 0.3145 \\
\hline \multirow[t]{2}{*}{ Caps } & $-0.0610^{* * *}$ & $-0.0613 * * *$ & $-0.0587^{* * *}$ & $-0.0590^{* * *}$ \\
\hline & 0.0083 & 0.0084 & 0.0087 & 0.0087 \\
\hline \multirow[t]{2}{*}{ Goal } & 0.0113 & 0.0129 & 0.0063 & 0.0079 \\
\hline & 0.0851 & 0.0851 & 0.0848 & 0.0849 \\
\hline \multirow[t]{2}{*}{ Assist } & 0.0385 & 0.0389 & 0.0269 & 0.0271 \\
\hline & 0.0629 & 0.0632 & 0.0637 & 0.0640 \\
\hline \multirow[t]{2}{*}{ Grade } & 0.0749 & 0.0760 & 0.0774 & 0.0787 \\
\hline & 0.0793 & 0.0795 & 0.0786 & 0.0788 \\
\hline \multirow[t]{2}{*}{ Popularity } & 0.0356 & 0.0355 & 0.0400 & 0.0398 \\
\hline & 0.0690 & 0.0693 & 0.0690 & 0.0694 \\
\hline \multirow[t]{2}{*}{ Reoccurrence } & 0.2779 & 0.2741 & 0.2859 & 0.2819 \\
\hline & 0.2080 & 0.2088 & 0.2111 & 0.2119 \\
\hline \multirow[t]{2}{*}{ Yellow cards } & $0.5388 * * *$ & $0.5510 * * *$ & $0.5140 * * *$ & $0.5266^{* * *}$ \\
\hline & 0.1595 & 0.1585 & 0.1572 & 0.1563 \\
\hline Injury timing & No & No & Yes & Yes \\
\hline Team FE & No & Yes & No & Yes \\
\hline$N$ & 1099 & 1099 & 1099 & 1099 \\
\hline$F$-statistic & 20.23 & 20.45 & 18.34 & 18.62 \\
\hline
\end{tabular}

Notes: $* * *, * *, *$ indicate significance at $1 \%, 5 \%$ and $10 \%$, respectively.

Standard Errors in italics. 
TABLE A.3

Effects of injury and other covariates on future productivity measures and injuries. Fixed effects estimates.

\begin{tabular}{|c|c|c|c|c|c|c|}
\hline & $\begin{array}{l}\text { (1) } \\
\text { Ln(Minutes played) }\end{array}$ & $\begin{array}{l}\text { (2) } \\
\text { Caps }\end{array}$ & $\begin{array}{l}\text { (3) } \\
\text { Grade }\end{array}$ & $\begin{array}{l}\text { (4) } \\
\text { Assist }\end{array}$ & $\begin{array}{l}\text { (5) } \\
\text { Goal }\end{array}$ & $\begin{array}{l}\text { (6) } \\
\text { Injury }\end{array}$ \\
\hline Days-off $_{t-1}$ & $\begin{array}{l}-0.1121^{* *} \\
0.0457\end{array}$ & $\begin{array}{l}-0.6704^{* *} \\
0.2963\end{array}$ & $\begin{array}{c}-0.0505^{* *} \\
0.0252\end{array}$ & $\begin{array}{l}-0.1475^{* * *} \\
0.0514\end{array}$ & $\begin{array}{r}-0.2108 \\
0.1811\end{array}$ & $\begin{array}{r}-0.0282 \\
0.0184\end{array}$ \\
\hline Age & $\begin{array}{l}1.0240^{* * *} \\
0.2323\end{array}$ & $\begin{array}{l}11.2486^{* * *} \\
2.1535\end{array}$ & $\begin{array}{l}0.2277^{* *} \\
0.1090\end{array}$ & $\begin{array}{l}1.7446^{* * *} \\
0.4780\end{array}$ & $\begin{array}{l}2.3829 * * * \\
0.7267\end{array}$ & $\begin{array}{r}-0.0769 \\
0.1446\end{array}$ \\
\hline Age sq. & $\begin{array}{l}-0.0181^{* * *} \\
0.0040\end{array}$ & $\begin{array}{l}-0.2005^{* * *} \\
0.0382\end{array}$ & $\begin{array}{l}-0.0038^{* *} \\
0.0019\end{array}$ & $\begin{array}{l}-0.0309^{* * *} \\
0.0087\end{array}$ & $\begin{array}{l}-0.0408^{* * *} \\
0.0129\end{array}$ & $\begin{array}{l}0.0018 \\
0.0025\end{array}$ \\
\hline Injury timing & Yes & Yes & Yes & Yes & Yes & Yes \\
\hline$N$ & 1087 & 1087 & 1038 & 1087 & 1087 & 1038 \\
\hline
\end{tabular}

Notes: $* * *, * *, *$ indicate significance at $1 \%, 5 \%$ and $10 \%$, respectively.

The model includes the full set of controls: dummy for the team captain; number of caps in the league during the season; number of senior national team caps during the season; number of national under-21 team caps during the season; dummy for the reoccurrence of the same injury; season fixed effects. Standard Errors in italics.

Final Manuscript Received: September 2019

\section{References}

Adler, M. (1985). 'Stardom and talent', The American Economic Review, Vol. 75, pp. 208-212.

Alvaredo, F., Atkinson, A. B., Piketty, T. and Saez, E. (2013). 'The top 1 percent in international and historical perspective', The Journal of Economic Perspectives, Vol. 27, pp. 3-20.

Alvaredo, F., Chancel, L., Piketty, T., Saez, E., and Zucman, G. (Eds.). (2018). World Inequality Report 2018. Belknap Press, Cambridge, MA.

Atkinson, A. B. (2017). 'Pareto and the upper tail of the income distribution in the UK: 1799 to the present', Economica, Vol. 84, pp. 129-156.

Atkinson, A. B., Piketty, T. and Saez, E. (2011). 'Top incomes in the long run of history', Journal of Economic Literature, Vol. 49, pp. 3-71.

Bahr, R. and Krosshaug, T. (2005). 'Understanding injury mechanisms: a key component of preventing injuries in sport', British Journal of Sports Medicine, Vol. 39, pp. 324-329.

Blair, R. D. (2012), Sports Economics, Cambridge University Press, Cambridge.

Bound, J., Schoenbaum, M., Stinebrickner, T. R. and Waidmann, T. (1999). 'The dynamic effects of health on the labor force transitions of older workers', Labour Economics, Vol. 6, pp. 179-202.

Bryson, A., Frick, B. and Simmons, R. (2013). 'The returns to scarce talent: footedness and player remuneration in European soccer', Journal of Sports Economics, Vol. 14, pp. 606-628.

Cai, L. (2010). 'The relationship between health and labour force participation: evidence from a panel data simultaneous equation model', Labour Economics, Vol. 17, pp. 77-90.

Cai, L., Mavromaras, K. and Oguzoglu, U. (2014). 'The effects of health status and health shocks on hours worked', Health Economics, Vol. 23, pp. 516-528.

Cameron, A. C., and Trivedi, P. K. (2010). Microeconometrics Using Stata (Vol. 2). Stata press, College Station, TX.

Carmichael, F., Rossi, G., Simmons, R. (2012). Contract Duration and Player Performance in Italian Football, 4th European Conference in Sport Economics / XIV IASE, Birkbeck University of London.

Carrieri, V., Principe, F. and Raitano, M. (2018). 'What makes you "super-rich"? New evidence from an analysis of football players' earnings', Oxford Economic Papers, Vol. 70, pp. 950-973.

Charles, K. K. (2003). 'The longitudinal structure of earnings losses among work-limited disabled workers', Journal of Human Resources, Vol. 38, pp. 618-646. 
CIES Football Observatory (2018). Contract Policy: Spanish Giants Head the Table. Weekly Post, 222. http://www.football-observatory.com/IMG/sites/b5wp/2017/222/en/

Deaton, A. (2003). 'Health, inequality, and economic development', Journal of Economic Literature, Vol. 41, pp. 113-158.

Deloitte (2017).Football Money League. 20 ${ }^{\text {th }}$ Edition. Sports Business Group.

Disney, R., Emmerson, C. and Wakefield, M. (2006). 'Ill health and retirement in Britain: a panel data-based analysis', Journal of Health Economics, Vol. 25, pp. 621-649.

Franck, E. and Nüesch, S. (2012). 'Talent and/or popularity: what does it take to be a superstar?', Economic Inquiry, Vol. 50, pp. 202-216.

Franzini, M., Granaglia, E., and Raitano, M. (2016). Extreme Inequalities in Contemporary Capitalism: Should We be Concerned about the Rich? Springer, Berlin.

García-Gómez, P. and López Nicolás, Á. (2006). 'Health shocks, employment and income in the Spanish labour market', Health Economics, Vol. 15, pp. 997-1009.

García-Gómez, P., Van Kippersluis, H., O'Donnell, O. and Van Doorslaer, E. (2013). 'Long-term and spillover effects of health shocks on employment and income', Journal of Human Resources, Vol. 48, pp. 873-909.

Halla, M. and Zweimüller, M. (2013). 'The effect of health on earnings: Quasi-experimental evidence from commuting accidents', Labour Economics, Vol. 24, pp. 23-38.

Hanson, A., Jolly, N. A. and Peterson, J. (2017). 'Safety regulation in professional football: empirical evidence of intended and unintended consequences', Journal of Health Economics, Vol. 53, pp. 87-99.

Hawkins, R. D. and Fuller, C. W. (1999). 'A prospective epidemiological study of injuries in four English professional football clubs', British Journal of Sports Medicine, Vol. 33, pp. 196-203.

Healy, A. (2008). 'Do firms have short memories? Evidence from major league baseball', Journal of Sports Economics, Vol. 9, pp. 407-424.

Jones, A. M., Rice, N. and Roberts, J. (2010). 'Sick of work or too sick to work? Evidence on self-reported health shocks and early retirement from the BHPS', Economic Modelling, Vol. 27, pp. 866-880.

Kahn, L. M. (2000). 'The sports business as a labor market laboratory', The Journal of Economic Perspectives, Vol. 14, pp. 75-94.

Lee, J. and Kim, H. (2008). 'A longitudinal analysis of the impact of health shocks on the wealth of elders', Journal of Population Economics, Vol. 21, pp. 217-230.

Leive, A. (2018). 'Dying to win? Olympic Gold medals and longevity', Journal of Health Economics, Vol. 61, pp. 193-204.

Lindeboom, M. and Kerkhofs, M. (2009). 'Health and work of the elderly: subjective health measures, reporting errors and endogeneity in the relationship between health and work', Journal of Applied Econometrics, Vol. 24, pp. 1024-1046.

Lucifora, C. and Simmons, R. (2003). 'Superstar effects in sport: evidence from Italian soccer', Journal of Sports Economics, Vol. 4, pp. 35-55.

Mange, B. and Philips, D.C. (2016). 'Career interruption and productivity: evidence from major league baseball during the Vietnam War Era', Journal of Human Capital, Vol. 10, pp. 159-185.

Mitra, S., Palmer, M., Mont, D. and Groce, N. (2016). 'Can households cope with health shocks in Vietnam?', Health Economics, Vol. 25, pp. 888-907.

Mueller-Wohlfahrt, H. W., Haensel, L., Mithoefer, K., Ekstrand, J., English, B., McNally, S., Orchard, J., van Dijk, C.N., Kerkhoffs, G.M., Schamasch, P. and Blottner, D. (2012). 'Terminology and classification of muscle injuries in sport: a consensus statement', British Journal of Sports Medicine, bjsports-2012, Vol. 47, pp. 342-350.

Mullin, C. J. and Dunn, L. F. (2002). 'Using baseball card prices to measure star quality and monopsony', Economic Inquiry, Vol. 40, pp. 620-632.

Reilly, B., Witt, R. (2007). The Determinants of Base Pay and the Role of Race in Major League Soccer: Evidence from the 2007 League Season, School of Economics Discussion Papers 1907, School of Economics, University of Surrey.

Rosen, S. (1981). 'The economics of superstars', The American Economic Review, Vol. 71, pp. 845-858.

Send, J. (2016), Football and Money: Income Inequality in the German Bundesliga, https://the10thman blog.wordpress.com/ 
Staiger, D. and Stock, J. (1997). 'Instrumental variables regression with weak instruments', Econometrica, Vol. 65(3), 557-586.

Stoecker, C., Sanders, N. J. and Barreca, A. (2016). 'Success is something to sneeze at: Influenza mortality in cities that participate in the Super Bowl', American Journal of Health Economics, Vol. 2, pp. 125-143.

Szymanski, S. (2007). 'The economics of sport: an international perspective. By Robert Sandy, Peter J. Sloane and Mark S. Rosentraub', Economica, Vol. 74, pp. 376-378.

Trevisan, E. and Zantomio, F. (2016). 'The impact of acute health shocks on the labour supply of older workers: evidence from sixteen European countries', Labour Economics, Vol. 43, pp. 171-185.

Treme, J. and Allen, S. K. (2009). 'Widely received: payoffs to player attributes in the NFL', Economics Bulletin, Vol. 29, pp. 1631-1643.

Treme, J. and Allen, S. K. (2011). 'Press pass: payoffs to media exposure among National Football League (NFL) wide receivers', Journal of Sports Economics, Vol. 12, pp. 370-390.

Wagstaff, A. (2007). 'The economic consequences of health shocks: evidence from Vietnam', Journal of Health Economics, Vol. 26, pp. 82-100.

Wagstaff, A. and Lindelow, M. (2014). 'Are health shocks different? Evidence from a multishock survey in Laos', Health Economics, Vol. 23, pp. 706-718. 